\title{
A novel 14q13.1-21.1 deletion identified by CNV-Seq in a patient with brain-lung- thyroid syndrome, tooth agenesis and immunodeficiency
}

\author{
Xuyun $\mathrm{Hu}^{1 \dagger}$, Jun $\mathrm{Liu}^{2 \dagger}$, Ruolan Guo ${ }^{1}$, Jun Guo ${ }^{1}$, Zhipeng Zhao ${ }^{2}$, Wei $\mathrm{Li}^{1}$, Baoping $\mathrm{Xu}^{2^{*}}$ and Chanjuan Hao ${ }^{1^{*}}$
}

\begin{abstract}
Background: Chromosome 14q11-q22 deletion syndrome (OMIM 613457) is a rare genomic disorder. The phenotype heterogeneity depends on the deletion size, breakpoints and genes deleted. Critical genes like FOXG1, NKX2-1, PAX9 were identified.

Case presentation: We performed whole exome sequencing (WES) and copy number variation sequencing (CNVseq) for a patient with mild speech and motor developmental delay, short stature, recurrent pulmonary infections, tooth agenesis and triad of brain-lung-thyroid syndrome. By using CNV-seq, we identified a 3.1 Mb de novo interstitial deletion of the 14q13.2q21.1 region encompassing 17 OMIM genes including NKX2-1, PAX9 and NFKBIA. Our patient's phenotype is consistent with other published $14 \mathrm{q} 13$ deletion patients.

Conclusion: Our results showed the combination of WES and CNV-seq is an effective diagnostic strategy for patients with genetic or genomic disorders. After reviewing published patients, we also proposed a new critical region for $14 q 13$ deletion syndrome with is a more benign disorder compared to 14q11-q22 deletion syndrome.
\end{abstract}

Keywords: 14q13 deletion, CNV-seq, Brain-lung-thyroid syndrome, Immunodeficiency

\section{Background}

Chromosome 14q11-q22 deletion syndrome (OMIM 613457) is a genomic disorder characterized by microcephaly, dysmorphic facies, psychomotor delay and failure to thrive. The associated phenotype is heterogeneous, depending on the size and variable breakpoints [1-3]. Some major features can be explained by haploinsufficiency of critical genes like FOXG1, NKX2-1, PAX9, etc. $[4,5]$. Patients with interstitial deletions involving $14 \mathrm{q} 13.1 \mathrm{q} 21.1$ are rarely reported and all these patients had similar features. $N K X 2-1$ and $P A X 9$ in $14 \mathrm{q} 13$ are

\footnotetext{
*Correspondence: xubaopingbch@163.com; hchihchj@163.com

${ }^{+}$Xuyun $\mathrm{Hu}$ and Jun Liu contributed equally to this work.

${ }^{2}$ China National Clinical Research Center of Respiratory Diseases, Respiratory

Department of Beijing Children's Hospital, Capital Medical University, National Center for Children's Health, Beijing 100045, China

${ }^{1}$ Beijing Key Laboratory for Genetics of Birth Defects, Beijing Pediatric Research Institute; MOE Key Laboratory of Major Diseases in Children; Genetics and Birth Defects Control Center, Beijing Children's Hospital, Capital Medical University, National Center for Children's Health, Beijing 100045, China
}

(c) The Author(s). 2019 Open Access This article is distributed under the terms of the Creative Commons Attribution 4.0 International License (http://creativecommons.org/licenses/by/4.0/), which permits unrestricted use, distribution, and reproduction in any medium, provided you give appropriate credit to the original author(s) and the source, provide a link to the Creative Commons license, and indicate if changes were made. The Creative Commons Public Domain Dedication waiver (http://creativecommons.org/publicdomain/zero/1.0/) applies to the data made available in this article, unless otherwise stated. considered to be the critical genes causing brain-lungthyroid syndrome (BLTS, OMIM 610978) and tooth agenesis (OMIM 604625) features, respectively [6, 7]. More recently, NFKBIA was purposed to be responsible for immunodeficiency these patients [8].

In our study, we report a new patient with 14q13.1q21.1 distal microdeletion syndrome. Copy number variation sequencing ( $\mathrm{CNV}$-seq) revealed a de novo 3.10 Mb sized deletion (chr14: 35,268,524-38,367,321). We detailed described this patient's phenotype and reviewed all reported patients with similar breakpoints encompassing NFKBIA, NKX2-1 and PAX9, and provided more information of relationships between clinical features and deleted genes.

The patient is a 15-year-old female born to nonconsanguineous parents by nature labor after full-term gestation. Family history is unremarkable. She was diagnosed

\section{Case presentation}


as aspiration pneumonia at birth and stayed in hospital for 4 days. Developmental delay was noticed after birth. She could not sit until 12 months. She could speak after 24 months and walk after 27 months. Dysarthria and ataxia were also unnoticed since after. At the age of 2 years, she went to hospital for speech and motor developmental delay. The symptoms were relieved after rehabilitation training. She was also diagnosed as short stature when she was 14 and received growth hormone therapy for 9 months. Her height increased from $132 \mathrm{~cm}$ $(-4.7 \mathrm{SD})$ to $142 \mathrm{~cm}(-3.2 \mathrm{SD})$, resulting in an annual growth velocity of $13 \mathrm{~cm}$.

At the age of 15 years, she was referred to the Department of Respiration, Beijing Children's Hospital for continuous cough and expectoration for 3 years. Her height and weight were below 3rd percentile. She did not have obvious facial anomalies but hypohidrosis and tooth agenesis (missing secondary dentition including molars and premolars) were noticed (Fig. 1a-c). She also had punctate pigmentation was noticed on her back. Mental development was delayed compared to peer children. Immune system examination revealed decreased IgG $(3.69 \mathrm{~g} / \mathrm{L})$, other immunoglobulins and lymphocyte subsets were normal. Paranasal sinusitis and anemia were diagnosed. She had increased thyroid-stimulating hormone (TSH, $11.983 \mathrm{mIU} / \mathrm{L}$ ), deceased triiodothyronine (T3, $58.79 \mathrm{ng} / \mathrm{dL}$ ) and normal tetraiodothyronine (T4, $4.81 \mu \mathrm{g} / \mathrm{dL}$ ), indicating a compensated hypothyroidism. She also had delayed development of the secondary sexual characters. Till this visit, she did not have menarche when she was 15 . Her bone age was also delayed $(\mathrm{BA}=10)$.

Thoracic computed tomography (CT) revealed interstitial and parenchymal lesions and bronchiectasis in both lungs, dominated with interstitial lesions, and mucus plugs was found in right upper lobe and left lower lobe (Fig. 1d). Ultrasonography of knee joint showed very limited amount of effusion in bilateral suprapatellar capsule. Routine blood test, coagulation function, and screening for infectious diseases, abdominal ultrasonography, ultrasonic cardiography, cranial $\mathrm{CT}$ and paranasal sinus $\mathrm{CT}$ were all normal.

DNA was isolated from peripheral blood samples obtained from the proband and her parents by using Gentra Puregene Blood Kit (QIAGEN, Hilden, Germany). $200 \mathrm{ng}$ genomic DNA of each individual was sheared by Biorupter (Diagenode, Belgium) to acquire 150 200 bp fragments. The ends of DNA fragment were repaired and Illumina Adaptor was added (Fast Library Prep Kit, iGeneTech, Beijing, China). After sequencing library
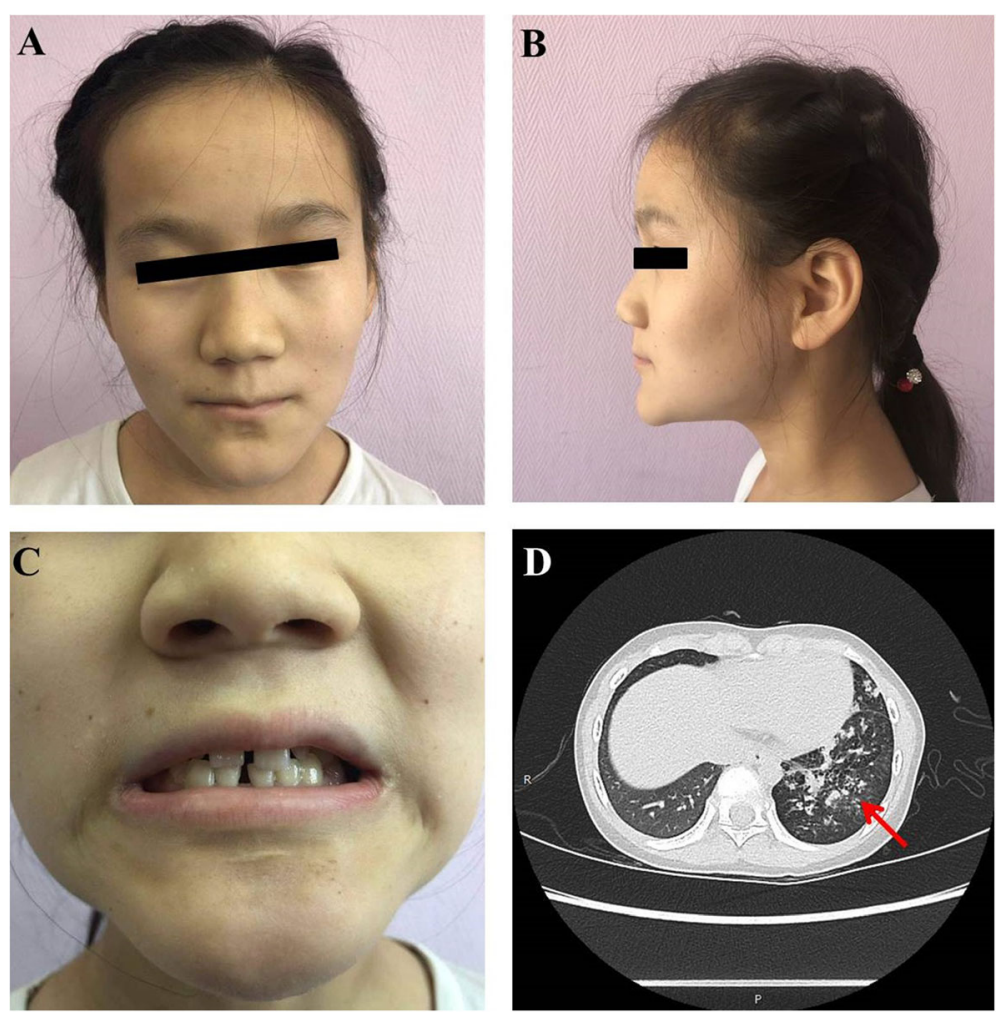

Fig. 1 Phenotype of the patient. a-b This patient did not have characteristic facial feathers of 14q11-q22 deletion syndrome. c The patient had normal primary dentition and agenesis of permanent teeth. $\mathbf{d}$ Thoracic CT showed interstitial and parenchymal lesions and bronchiectasis in both lungs (red arrow) 
were constructed, the whole exome was captured with AIExome Enrichment Kit V1 (iGeneTech, Beijing, China) and sequenced on Illumina NovaSeq 6000 (Illumina, San Diego, CA) with with 150 base paired-end reads. Raw reads were filtered to remove low quality reads by using FastQC. Clean reads were mapped to the reference genome GRCh37. Single nucleotide variants (SNVs) were annotated and filtered by TGex (http://app. genecards.cn) and classified following the American College of Medical Genetics and Genomics and the Association for Molecular Pathology interpretation standards and guidelines [9]. To identify large copy number variations $(\mathrm{CNVs})$, part of the sequencing library was sequenced directly on Illumina NovaSeq 6000 and each sample yielded one Gigabase Raw data. An in-house pipeline was applied to map and call CNVs and the health parents were used as control samples [10]. Clean reads were mapped to the reference genome GRCh37. Database of Genomic Variants, DECIPHER database, ClinVar, OMIM and ClinGen were used for interpretation and classification of the clinical significance of candidate CNVs according to previously reported guidelines [11]. By whole exome sequencing (WES), 30,636 SNVs and small indels were called from 14,549.59 Mb Clean bases (Target mean depth was 122.23X) in the proband. After analysis and interpretation, none of these variants could explain the proband's phenotype. However, CNVseq revealed a de novo $3.1 \mathrm{Mb}$ deletion on 14q13.1q21.1 (chr14: 35,268,524-38,367,321) (Fig. 2). The deletion encompasses 17 OMIM genes including BAZ1A, SRP54, PPP2R3C, KIAA0391, PSMA6, NFKBIA, INSM2, RALGAPA1, PTCSC3, MBIP, SFTA3, NKX2-1, NKX2-8, PAX9, SLC25A21, MIPOL1 and FOXA1. The deletion was not present in the parents. WES reads depth data was used to validate this deletion $(\log 2=-1.00428$, mean depth $=50.02 \mathrm{X}$, probes number $=379)$. Informed consent was obtained from the parents of the patient.

\section{Discussion and conclusions}

In this study, we described clinical and molecular findings in a female with mild speech and motor developmental delay, short stature, recurrent pulmonary infections, tooth agenesis and triad of BLTS. Using $\mathrm{CNV}$-seq, we identified a $3.1 \mathrm{Mb}$ de novo interstitial deletion of the 14q13.2q21.1 region encompassing 17 OMIM genes.

The prevalence of chromosome 14q11-q22 deletion syndrome is lower than 1 in 1,000,000 infancies. The phenotype of patients is largely determined by the deletion size and breakpoints. Several candidate genes were well identified like FOXG1, NKX2-1 and PAX9. Deletions including FOXG1 and a $1 \mathrm{Mb}$ upstream region on $14 \mathrm{q} 12$ cause severe intellectual disability $[5,12-16]$. NKX2-1 (14q13.3) deletion is responsible for choreoathetosis, hypothyroidism, short stature and neonatal respiratory distress and haploinsufficiency of PAX9 (14q13.3) causes oligodontia phenotype [5, 17-21]. The role of other genes is still under evaluation. NPAS3 (14q13.1) encodes a transcription factor localized to the nucleus and may regulate genes involved in neurogenesis. Npas $3^{-1-}$ mice had abnormal neurodevelopment, neurosignaling and behavior [22], making it a candidate gene of holoprosencephaly (HPE) and hypoplasia of the corpus callosum (ACC) in 14q11-q22 deletion syndrome patients [5, 23]. RALGAPA1 (14q13.2) encodes a major subunit of the RAL-GTPase activating protein, and was

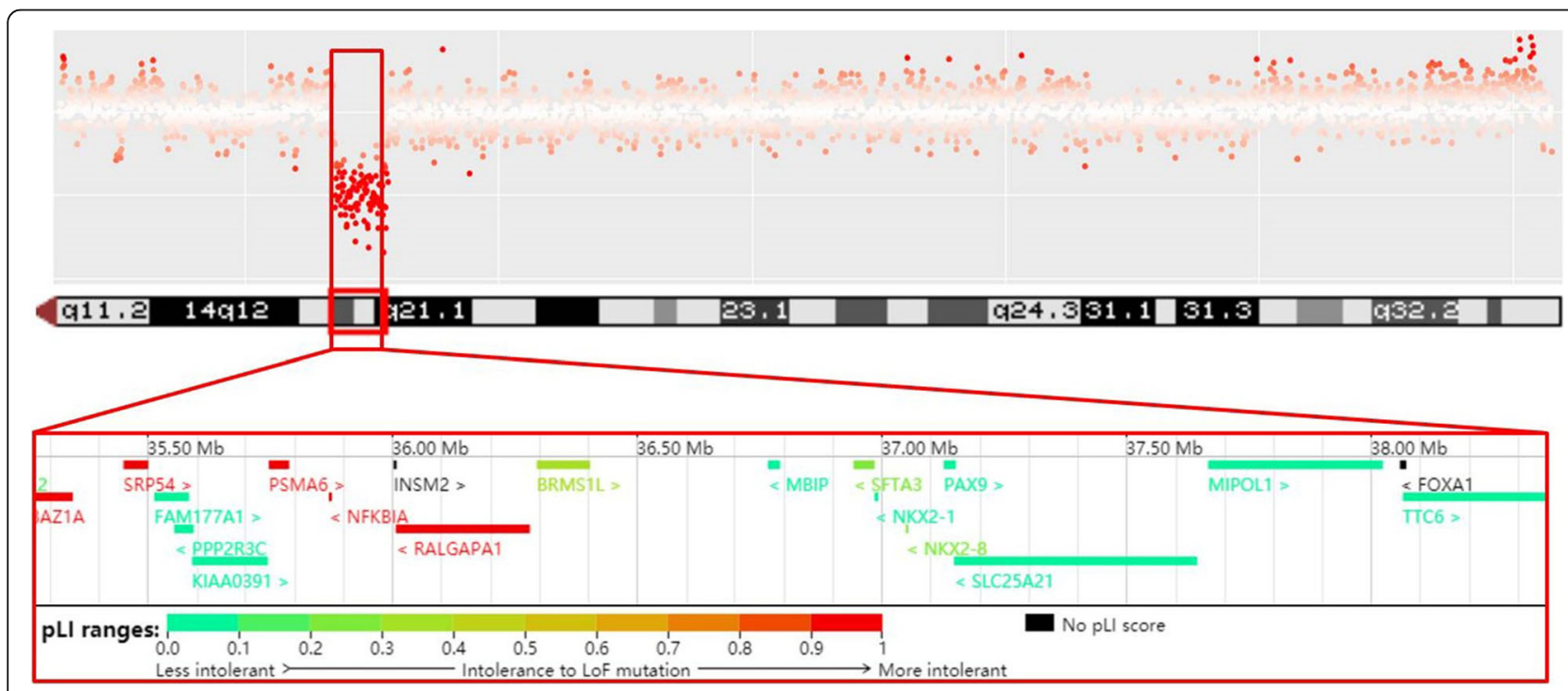

Fig. 2 A de novo 3.1 Mb deletion on 14q13.1q21.1 was identified in the patient. The deletion encompasses 17 OMIM genes and the pLI (probability of LoF intolerant) value of each gene is shown in colors. The deletion shown is detected by CNV-seq 
suggested to be important in brain development [24]. NFKBIA (14q13.2) mutation cause dominant inherited ectodermal dysplasia and immunodeficiency 2 (EDAID2, OMIM 612132) and may be the explanations of patients' immunological features [4, 8]. SEC23A (14q21.1) encodes a subunit of a protein complex and found in the ribosome-free transitional face of the endoplasmic reticulum and associated vesicle and it is considered as a candidate gene of joint hyperlaxity [8, 17]. Mice with knock-out had abnormal cartilage development and collagen level [25]. Biallelic SEC23A mutation causes craniolenticulosutural dysplasia (OMIM 607812). It is characterized by facial dysmorphism, late-closing fontanels, cataract, and skeletal defects including joint laxity [26].

The deletion region of our patient (chr14: 35,268,52438,367,321) encompasses RALGAPA1 and NFKBIA but no NPAS3 or SEC23A. Consequently, joint laxity, HPE or ACC was not observed in our patient. Epilepsy was also absent in our patient even though RALGAPA1 was deleted. We reviewed published ten patients with phenotype description and similar deletion regions encompassing RALGAPA1, the deleted sizes ranged from $0.82 \mathrm{Mb}$ to $6.98 \mathrm{Mb}$, and only one patient with $1.99 \mathrm{Mb}$ deletion reported by Caliebe $A$ et al. had seizures $[4,5,8,19,23$, 27-29]. Therefore, deletion of RALGAPA1 was not sufficient to cause seizures and the genotype-phenotype correlation of RALGAPA1 deletion remained unclear. Considering our patient had decreased IgG, paranasal sinusitis and recurrent infections, we also reviewed immunological features of seven patients with NFKBIA deletion (two patients were collected from DECIPHER database, Fig. 3). Patient reported by Villafuerte B et al. also had low IgG but also relatively low lymphocyte count and percentage of switched B cells [8]. Gentile M patient also had recurrent infections, with a mild reduction of $\mathrm{CD} 3 / \mathrm{CD} 8$ lymphocytes and an elevation of CD4/
CD8 ratio, yet her IgA, IgG, and IgM were normal [4]. Santen G patient 5 and Peall $\mathrm{K}$ patient 4 had recurrent lower respiratory infections $[5,19]$. Patient 256,879 from DECIPHER database also had recurrent infections. We next reviewed seven patients with $P A X 9, N K X 2-1$ deletion and leaving NFKBIA intact in previously literature. The deleted sizes ranged from $0.36 \mathrm{Mb}$ to $3.69 \mathrm{Mb}$, and only one male with $2.34 \mathrm{Mb}$ had recurrent bronchitises $[5,17,19,20,29]$. It was notable that the pLI (probability of LoF intolerant) value of NFKBIA was 1 , and the o/ e score is $0(0-0.19)$, indicating deletion of this gene may have serious clinical consequences. In addition, three NFKBIA nonsense variants were reported in patients with EDAID2 [30]. To this respect, NFKBIA haploinsufficiency may be an appropriate explanation of the immunological features of 14q13 deletion patients.

Our patient, together with previously reported patients, identified a well-defined, more benign, 14q13 distal microdeletion syndrome. The major phenotype includes choreoathetosis, tooth agenesis, pulmonary dysfunction, immunological abnormal and hypothyroidism. The 1.4 Mb critical region contained at least three candidate genes: NFKBIA, NKX2-1 and PAX9 (Fig. 3). In this region, one more gene, PSMA6, with its PLI being 1 and $\mathrm{o} / \mathrm{e}$ score being $0(0-0.23)$, should be more attention. PSMA6 encodes the component of the $20 \mathrm{~S}$ core proteasome complex involved in the proteolytic degradation of most intracellular proteins. Variants in PSMA6 were reported to be associated with inflammation diseases like myocardial infarction [31], arthritis [32, 33], etc. Given its essential function and intolerant of LoF variants in population, more subtle features may be uncovered in the future.

Previous researches have demonstrated that $\mathrm{CNV}$ occurred in $5-10 \%$ of the total human genome [34], and chromosomal microarray analysis (CMA), as a stable and accurate platform, is used for detecting. Currently,

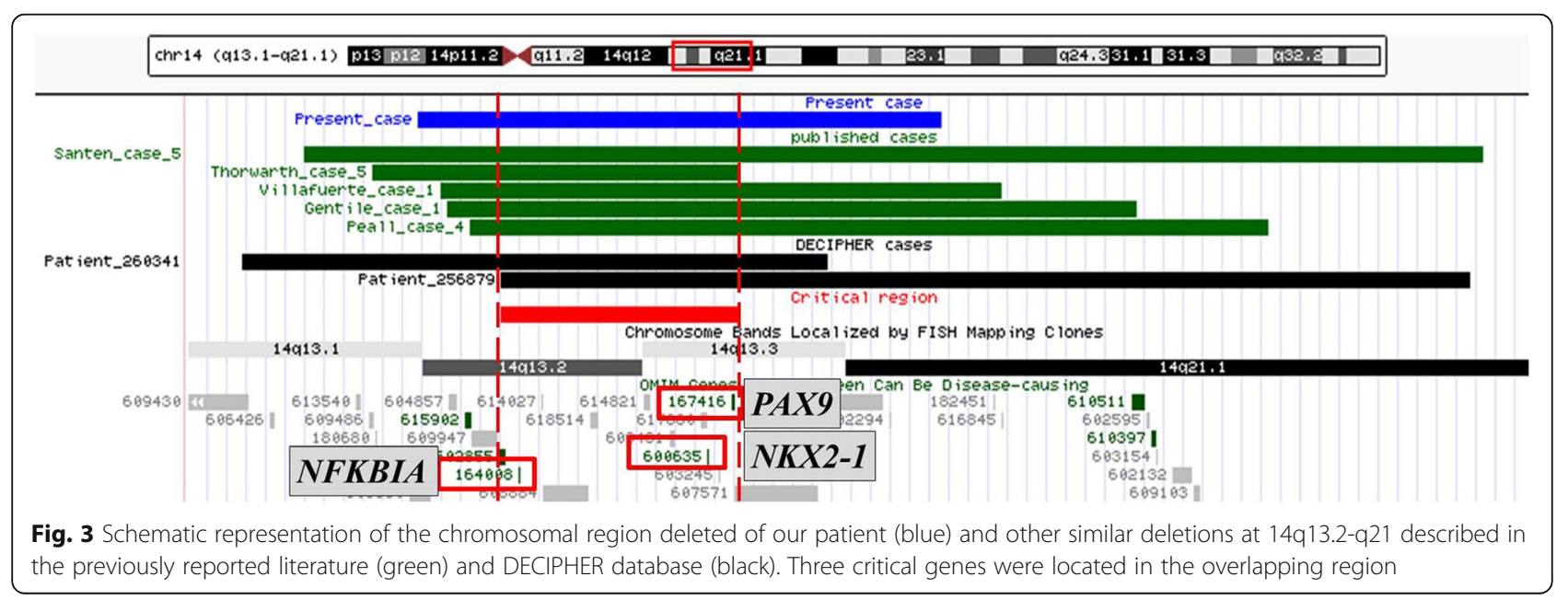


CNV-seq is developed by analyzing data generated from WES or whole genome sequencing (WGS) [35-37]. Recent studies showed that the combination of WES and $\mathrm{CNV}$-seq by low cover genome sequencing increased diagnostic yield in patients with rare diseases [38, 39]. In our study, after suspecting the diagnosis of BLTS of our patient, we performed trio-WES and low coverage WGS (0.3X) simultaneously. No putative pathogenic variants in $N K X 2-1$ was identified, but we uncovered a $3.1 \mathrm{Mb}$ deletion encompassing $N K X 2-1$, as well as PAX9 and NFKBIA. Notably, WES data could be applied to CNV identification, so we used WES data to validate this deletion. By reviewing our deleted region and other reported patients, we proposed a $1.4 \mathrm{Mb}$ critical region for $14 \mathrm{q} 13$ distal microdeletion syndrome with a well-defined, more benign phenotype compared to 14q11-q22 deletion syndrome. Our results further demonstrated the clinical utility of the diagnostic strategy combining WES and $\mathrm{CNV}$-seq for genetic diseases patients.

\section{Abbreviations}

ACC: Hypoplasia of the corpus callosum; BLTS: Brain-lung-thyroid syndrome; CMA: Chromosomal microarray analysis; CNVs: Copy number variations; CNVseq: Copy number variation sequencing; CT: Computed tomography; HPE: Holoprosencephaly; pLI: Probability of LoF intolerant; SNVs: Single nucleotide variants; WES: Whole exome sequencing; WGS: Whole genome sequencing

\section{Acknowledgements}

We thank the patient and the parents for their participation.

\section{Authors' contributions}

XH drafted the manuscript and analyzed WES and CNV-seq data. RG and JG performed molecular experiments. $J$ and ZZ performed the clinical examination of the patient and his family. WL performed data interpretation and reviewed the manuscript. BX and $\mathrm{CH}$ managed the patient and critically revised the paper. All authors read and approved the final manuscript.

\section{Funding}

This work was partially supported by grants from the Ministry of Science and Technology of China (2016YFC1000306), the Beijing Municipal Science and Technology Commission Foundation (Z181100001918003), the Beijing Municipal Commission of Health and Family Planning Foundation (2018-2 $1141)$ and the Special Fund of the Pediatric Medical Coordinated Development Center of Beijing Hospitals Authority (XTCX201807)

\section{Availability of data and materials}

The datasets used and/or analyzed during the current study are available from the corresponding author on reasonable request.

\section{Ethics approval and consent to participate}

The study was approved by the Ethics Committee of Beijing Children's Hospital, Capital Medical University.

\section{Consent for publication}

Informed consent was obtained from the parents of the patient.

\section{Competing interests}

The authors declare that they have no competing interests.
Received: 14 August 2019 Accepted: 2 December 2019

Published online: 19 December 2019

\section{References}

1. Grammatico P, de Sanctis S, di Rosa C, Cupilari F, del Porto G. First case of deletion 14q11.2q13: clinical phenotype. Ann Genet. 1994;37(1):30-2.

2. Kamnasaran D, O'Brien PC, Schuffenhauer S, Quarrell O, Lupski JR, Grammatico P, et al. Defining the breakpoints of proximal chromosome 14q rearrangements in nine patients using flow-sorted chromosomes. Am J Med Genet. 2001;102(2):173-82

3. Torgyekes E, Shanske AL, Anyane-Yeboa K, Nahum O, Pirzadeh S, Blumfield E, et al. The proximal chromosome 14q microdeletion syndrome: delineation of the phenotype using high resolution SNP oligonucleotide microarray analysis (SOMA) and review of the literature. Am J Med Genet A. 2011;155A(8):1884-96.

4. Gentile M, De Mattia D, Pansini A, Schettini F, Buonadonna AL, Capozza M, et al. 14q13 distal microdeletion encompassing NKX2-1 and PAX9: patient report and refinement of the associated phenotype. Am J Med Genet A. 2016;170(7):1884-8.

5. Santen GW, Sun Y, Gijsbers AC, Carre A, Holvoet M, Haeringen A, et al. Further delineation of the phenotype of chromosome $14 q 13$ deletions: (positional) involvement of FOXG1 appears the main determinant of phenotype severity, with no evidence for a holoprosencephaly locus. J Med Genet. 2012:49(6):366-72

6. Devriendt K, Vanhole C, Matthijs G, de Zegher F. Deletion of thyroid transcription factor-1 gene in an infant with neonatal thyroid dysfunction and respiratory failure. N Engl J Med. 1998;338(18):1317-8.

7. Stockton DW, Das P, Goldenberg M, D'Souza RN, Patel PI. Mutation of PAX9 is associated with oligodontia. Nat Genet. 2000;24(1):18-9.

8. Villafuerte B, Natera-de-Benito D, Gonzalez A, Mori MA, Palomares M, Nevado J, et al. The brain-lung-thyroid syndrome (BLTS): a novel deletion in chromosome 14q13.2-q21.1 expands the phenotype to humoral immunodeficiency. Eur J Med Genet. 2018:61 (7):393-8.

9. Richards S, Aziz N, Bale S, Bick D, Das S, Gastier-Foster J, et al. Standards and guidelines for the interpretation of sequence variants: a joint consensus recommendation of the American College of Medical Genetics and Genomics and the Association for Molecular Pathology. Genet Med. 2015;17(5):405-24.

10. Xie C, Tammi MT. CNV-seq, a new method to detect copy number variation using high-throughput sequencing. BMC Bioinformatics. 2009;10:80.

11. Kearney HM, Thorland EC, Brown KK, Quintero-Rivera F, South ST. Working Group of the American College of medical genetics laboratory quality assurance C. American College of Medical Genetics standards and guidelines for interpretation and reporting of postnatal constitutional copy number variants. Genet Med. 2011:13(7):680-5.

12. Kortum F, Das S, Flindt M, Morris-Rosendahl DJ, Stefanova I, Goldstein A, et al. The core FOXG1 syndrome phenotype consists of postnatal microcephaly, severe mental retardation, absent language, dyskinesia, and corpus callosum hypogenesis. J Med Genet. 2011:48(6):396-406.

13. Ibn-Salem J, Kohler S, Love Ml, Chung HR, Huang N, Hurles ME, et al. Deletions of chromosomal regulatory boundaries are associated with congenital disease. Genome Biol. 2014;15(9):423.

14. Ellaway CJ, Ho G, Bettella E, Knapman A, Collins F, Hackett A, et al. 14q12 microdeletions excluding FOXG1 give rise to a congenital variant Rett syndrome-like phenotype. Eur J Hum Genet. 2013;21(5):522-7.

15. Cellini E, Vignoli A, Pisano T, Falchi M, Molinaro A, Accorsi P, et al. The hyperkinetic movement disorder of FOXG1-related epileptic-dyskinetic encephalopathy. Dev Med Child Neurol. 2016:58(1):93-7.

16. Allou L, Lambert L, Amsallem D, Bieth E, Edery P, Destree A, et al. 14q12 and severe Rett-like phenotypes: new clinical insights and physical mapping of FOXG1-regulatory elements. Eur J Hum Genet. 2012;20(12):1216-23.

17. Dale RC, Grattan-Smith P, Nicholson M, Peters GB. Microdeletions detected using chromosome microarray in children with suspected genetic movement disorders: a single-Centre study. Dev Med Child Neurol. 2012:54(7):618-23.

18. Gras D, Jonard L, Roze E, Chantot-Bastaraud S, Koht J, Motte J, et al. Benign hereditary chorea: phenotype, prognosis, therapeutic outcome and long term follow-up in a large series with new mutations in the TITF1/NKX2-1 gene. J Neurol Neurosurg Psychiatry. 2012;83(10):956-62.

19. Peall KJ, Lumsden D, Kneen R, Madhu R, Peake D, Gibbon F, et al. Benign hereditary chorea related to NKX2.1: expansion of the genotypic and phenotypic spectrum. Dev Med Child Neurol. 2014;56(7):642-8. 
20. Hayashi S, Yagi M, Morisaki I, Inazawa J. Identical deletion at 14q13.3 including PAX9 and NKX2-1 in siblings from mosaicism of unaffected parent. J Hum Genet. 2015;60(4):203-6.

21. Das P, Stockton DW, Bauer C, Shaffer LG, D'Souza RN, Wright T, et al. Haploinsufficiency of PAX9 is associated with autosomal dominant hypodontia. Hum Genet. 2002;110(4):371-6.

22. Brunskill EW, Ehrman LA, Williams MT, Klanke J, Hammer D, Schaefer TL, et al. Abnormal neurodevelopment, neurosignaling and behaviour in Npas3-deficient mice. Eur J Neurosci. 2005;22(6):1265-76.

23. Piccione M, Serra G, Consiglio V, Di Fiore A, Cavani S, Grasso M, et al. 14q13. 1-21.1 deletion encompassing the HPE8 locus in an adolescent with intellectual disability and bilateral microphthalmia, but without holoprosencephaly. Am J Med Genet A. 2012;158A(6):1427-33.

24. Shimojima K, Komoike Y, Tohyama J, Takahashi S, Paez MT, Nakagawa E, et al. TULIP1 (RALGAPA1) haploinsufficiency with brain development delay. Genomics. 2009;94(6):414-22.

25. Zhu M, Tao J, Vasievich MP, Wei W, Zhu G, Khoriaty RN, et al. Neural tube opening and abnormal extraembryonic membrane development in SEC23A deficient mice. Sci Rep. 2015;5:15471.

26. Boyadjiev SA, Kim SD, Hata A, Haldeman-Englert C, Zackai EH, Naydenov C, et al. Cranio-lenticulo-sutural dysplasia associated with defects in collagen secretion. Clin Genet. 2011:80(2):169-76.

27. Caliebe A, Martin Subero Jl, Muhle H, Gesk S, Janig U, Krause M, et al. A 2 $\mathrm{Mb}$ deletion in 14q13 associated with severe developmental delay and hemophagocytic lymphohistiocytosis. Eur J Med Genet. 2011;54(5):e505-9.

28. Kharbanda M, Hermanns P, Jones J, Pohlenz J, Horrocks I, Donaldson M. A further case of brain-lung-thyroid syndrome with deletion proximal to NKX2-1. Eur J Med Genet. 2017;60(5):257-60.

29. Thorwarth A, Schnittert-Hubener S, Schrumpf P, Muller I, Jyrch S, Dame C, et al. Comprehensive genotyping and clinical characterisation reveal 27 novel NKX2-1 mutations and expand the phenotypic spectrum. J Med Genet. 2014;51(6):375-87.

30. Petersheim D, Massaad MJ, Lee S, Scarselli A, Cancrini C, Moriya K, et al. Mechanisms of genotype-phenotype correlation in autosomal dominant anhidrotic ectodermal dysplasia with immune deficiency. J Allergy Clin Immunol. 2018;141(3):1060-73 e3.

31. Ozaki K, Sato H, lida A, Mizuno H, Nakamura T, Miyamoto Y, et al. A functional SNP in PSMA6 confers risk of myocardial infarction in the Japanese population. Nat Genet. 2006;38(8):921-5.

32. Sukhov A, Adamopoulos IE, Maverakis E. Interactions of the immune system with skin and bone tissue in psoriatic arthritis: a comprehensive review. Clin Rev Allergy Immunol. 2016;51(1):87-99.

33. Sjakste T, Paramonova N, Rumba-Rozenfelde I, Trapina I, Sugoka O, Sjakste N. Juvenile idiopathic arthritis subtype- and sex-specific associations with genetic variants in the PSMA6/PSMC6/PSMA3 gene cluster. Pediatr Neonatol. 2014;55(5):393-403.

34. Conrad DF, Pinto D, Redon R, Feuk L, Gokcumen O, Zhang Y, et al. Origins and functional impact of copy number variation in the human genome. Nature. 2010;464(7289):704-12.

35. Magi A, Tattini L, Cifola I, D'Aurizio R, Benelli M, Mangano E, et al. EXCAVATOR: detecting copy number variants from whole-exome sequencing data. Genome Biol. 2013;14(10):R120.

36. Marchuk DS, Crooks K, Strande N, Kaiser-Rogers K, Milko LV, Brandt A, et al. Increasing the diagnostic yield of exome sequencing by copy number variant analysis. PLoS One. 2018;13(12):e0209185.

37. Yao R, Zhang C, Yu T, Li N, Hu X, Wang X, et al. Evaluation of three readdepth based CNV detection tools using whole-exome sequencing data. Mol Cytogenet. 2017;10:30

38. Gao C, Wang X, Mei S, Li D, Duan J, Zhang P, et al. Diagnostic yields of trioWES accompanied by CNVseq for rare neurodevelopmental disorders. Front Genet. 2019:10:485.

39. Jiao Q, Sun H, Zhang H, Wang R, Li S, Sun D, et al. The combination of whole-exome sequencing and copy number variation sequencing enables the diagnosis of rare neurological disorders. Clin Genet. 2019;96(2):140-50.

\section{Publisher's Note}

Springer Nature remains neutral with regard to jurisdictional claims in published maps and institutional affiliations.

Ready to submit your research? Choose BMC and benefit from:

- fast, convenient online submission

- thorough peer review by experienced researchers in your field

- rapid publication on acceptance

- support for research data, including large and complex data types

- gold Open Access which fosters wider collaboration and increased citations

- maximum visibility for your research: over $100 \mathrm{M}$ website views per year

At BMC, research is always in progress.

Learn more biomedcentral.com/submissions 